\title{
Caesarean in Rural Environment of Eastern Kasaï (Dr Congo): Evolution of Caesarean Section Rates in Kasansa and Tshilenge
}

\author{
André Guillaume Kabongo ${ }^{*}$, Dady Kalala1, Jean Christophe Bukasa1, Deca Blood Banza1, \\ Christine Kankologo' ${ }^{1}$, André Mutombo², Stany Wembonyama ${ }^{3}$ \\ ${ }^{1}$ Higher Institute of Medical Techniques of Mbuji Mayi, Mbuji Mayi, DR Congo \\ ${ }^{2}$ Department of Pediatrics, Official University of Mbuji Mayi, Mbuji Mayi, DR Congo \\ ${ }^{3}$ Department of Pediatrics and School of Public Health, University of Lubumbashi, Lubumbashi, DR Congo \\ Email: *guillaumemwamba25863@gmail.com
}

How to cite this paper: Kabongo, A.G., Kalala, D., Bukasa, J.C., Banza, D.B., Kankologo, C., Mutombo, A. and Wembonyama, S. (2018) Caesarean in Rural Environment of Eastern Kasaï (Dr Congo): Evolution of Caesarean Section Rates in Kasansa and Tshilenge. Open Access Library Journal, 5: e4564.

https://doi.org/10.4236/oalib.1104564

Received: April 3, 2018

Accepted: April 26, 2018

Published: April 29, 2018

Copyright ( 2018 by authors and Open Access Library Inc.

This work is licensed under the Creative Commons Attribution International License (CC BY 4.0).

http://creativecommons.org/licenses/by/4.0/

\section{(c) (i) Open Access}

\begin{abstract}
Objective: To analyze the evolution monthly of the disastrous Caesarean and to their influence one maternal mortality and infantile in the General hospitals of reference of Kasansa and Tshilenge. Methods: Descriptive retrospective study Bi-centric related to 434 Caesareans carried out to the maternity of the general hospital of reference of Kasansa and that of Tshilenge during years 2015 and 2016. Our dated were collected in the obstetric files, registers of the maternity and the operating room. Public garden Ki square is used to compare it with the percentages and $\mathrm{T}$ of Student for the comparison of the averages in two maternities, and the percentage of increase gold reduction was calculated with the formulated of growth used also in economy. Results: Two maternities received respectively in 2015, 549 and 227 childbirth, among which 136 Caesareans carried out with Kasansa and 72 in Tshilenge. During the Disastrous months (from January to December), Caesareans dropped by $68.2 \%$, (10.7\% to $3.4 \%$ ) in Kasansa and of $71.1 \%$ with Tshilenge (from $19.7 \%$ to 2.8\%). In 2016, 702 childbirth and 109 Caesareans with Kasansa and 376 childbirth and 117 Caesareans with Tshilenge. Disastrous Caesarean dropped by $7 \%$ (from $12.8 \%$ to $11.9 \%$ ) with Kasansa and raised of $143.3 \%$ with Tshilenge (from $6 \%$ to $14.6 \%$ ). Perinatal mortality dropped by $69.5 \%$ in 2015 and $51.8 \%$ in 2016 and maternal mortality dropped respectively by $100 \%$ in 2015 and in 2016 of $35.9 \%$. Conclusion: During 24 months concerned with the study (of January 2015 with December 2016), the practice of the Caesarean Knew has fell into the two structures except for maternity of Tshilenge 2016. Thus, the improvement of the maternal forecast master keys rather by year improvement of the quality of the obstetric assumption of responsibility but
\end{abstract}


not by the increase amongst operational childbirth. Thesis results encourage custom to analyze the participation of the various disastrous indications in the variation of the Caesarean in this medium.

\section{Subject Areas}

Public Health

\section{Keywords}

Caesarean, Failure, Evolution, Kasansa, Tshilenge

\section{Introduction}

Caesarean section is recognized as an effective surgical procedure to reduce maternal and newborn mortality if it is practiced in time for pregnant women who really need it. This is the case, for example, for patients whose work is too long or when delivery is slow in coming and the fetus lacks oxygen. However, at a time when the incidence of caesarean section is increasing worldwide [1] [2] [3] [4], in these considered disadvantaged areas of sub-Saharan Africa, the coverage of needs in this intervention is still lower in relation to the WHO minimum threshold of 5\% [5] [6]. It is difficult for a large number of women living in this area to quickly access a caesarean section because the costs of the act and transportation to the hospital remain too high. This difficulty of access is associated with the risk and safety associated with caesarean delivery that differs from one place to another in the world [7]. In developing countries, including the Democratic Republic of Congo, which are still excluded from scientific and technological advances, caesarean section remains a dangerous operation for the mother-child couple. Different studies across sub-Saharan Africa show high maternal and perinatal morbidity and mortality [8] [9] [10] [11] [12].

To reduce this financial barrier, the Democratic Republic of Congo, like some African countries, has decided, with the help of partners, to partially or totally fund some obstetric care. This was the case in some rural areas of Kasai Oriental, including Kasansa and Tshilenge since the end of 2014.

As the subsidy has increased caesarean section rates in some countries after implementation [13], no study has shown either its increase or its impact on maternal and newborn mortality in Kasansa and Tshilenge. On the other hand, it is also not known whether, in this context, the indications for cesarean sections were well posed, according to objective clinical criteria, or conversely if some caesarean sections were performed without real medical reasons.

The objective of this study is to analyze the monthly evolution of the rates as well as their influence on maternal and perinatal mortality at Kasansa and Tshilenge HGR. 


\section{Methods}

This bi-centric descriptive and retrospective study focused on 434 cesarean sections performed at the Maternity Hospital of Kasansa Reference General Hospital and that of Tshilenge General Hospital during 2015 and 2016 (24 months). The sources of our data are obstetric records, maternity and operating room registers, operative records and newborn records. These hospital data were recorded on the survey card. The variables studied were: maternal age, parity, caesarean section (caesarean section uterus), gestational age, indications for caesarean section and Maternal and perinatal prognosis. This study excludes any patient who has been operated on in another surgical structure and who has been trained in the structures under study for management.

Their analysis was done using Epi info 2007 software and the Excel 2007 software was used to plot the graphs. The t-Student and Khi-square tests were used respectively to compare the average rates in the two maternities.

\section{Ethical Considerations}

The data of this study being intended for scientific purposes, the principle of anonymity was respected and the study obtained the approval of the interuniversity ethics committee of the city of Mbujimayi (Kasai Oriental/DR Congo).

\section{Results}

\subsection{Patient Description}

The results in this table (Table 1) indicate that the difference was significant in both structures in terms of mean maternal age $(p=0.223)$, parity $(p=0.340)$ and gestational age $(\mathrm{p}=0.088)$ because $\mathrm{p}>0.05$. Caesarean sections performed on the scarred uterus was $14.7 \%$ overall. The prevalence of iterative caesarean was no different to Kasansa and Tshilenge (15.7\% against $13.2 \%$; $\mathrm{p}=0.539$ ).

The results in this table (Table 2) indicate that in Kasansa and Tshilenge there was no significant difference in maternal mortality $(\mathrm{p}=0.7844)$; however, more perinatal deaths were recorded in Tshilenge (7.1\%) in Kasansa (4.8\%), very significant statistical difference $(\mathrm{p}=0.0000)$.

\subsection{Monthly Evolution of Caesarean Section Rates}

In 2015, Kasansa maternity hospital, 36 deliveries were recorded in January and 78 in December, caesareans saw a sharp decline, from $10.7 \%$ at the beginning of the year to $3.4 \%$ at the end (Figure 1). The Tshilenge Maternity Hospital registered 31 deliveries at the beginning of the year and 16 deliveries at the end. During the same period, caesarean section rates increased from $9.7 \%$ to $2.8 \%$ (Figure 2).

In 2016, deliveries at Kasansa Maternity Hospital increased from 64 in January to 74 in December and caesarean section rates from $12.8 \%$ to $11.9 \%$ (Figure 3 ). In Tshilenge, 20 deliveries were recorded in January and 50 in December and 6\% of cesarean deliveries were performed in January compared to $14.6 \%$ in December (Figure 4). 
Table 1. Characteristics of the patients.

\begin{tabular}{|c|c|c|c|c|c|c|c|}
\hline & \multicolumn{2}{|c|}{ Kasansa } & \multicolumn{2}{|c|}{ Tshilenge } & \multicolumn{2}{|c|}{ Total } & \multirow{2}{*}{ p-value } \\
\hline & Effective & $\%$ & Effective & $\%$ & Effective & $\%$ & \\
\hline Age & $\mathrm{n}=245$ & & $\mathrm{n}=189$ & & $n=434$ & & \\
\hline$<18$ years & 17 & 6.9 & 16 & 8.5 & 33 & 7.6 & 0.350 \\
\hline $18-35$ years & 183 & 74.7 & 121 & 64 & 304 & 70 & $0.016^{*}$ \\
\hline$>35$ years & 45 & 18.4 & 52 & 27.5 & 97 & 22.4 & $0.023^{*}$ \\
\hline $\begin{array}{c}\text { Mean and standard deviation } \\
\text { Parity }\end{array}$ & \multicolumn{2}{|c|}{$28.1 \pm 6.7$} & \multicolumn{2}{|c|}{$28.9 \pm 7.3$} & \multicolumn{2}{|l|}{$\mathrm{t}=0.223$} & 0.223 \\
\hline Primiparous & 47 & 19.2 & 46 & 24.3 & 93 & 21.4 & 0.194 \\
\hline Paucipares & 34 & 13.9 & 23 & 12.2 & 57 & 13.1 & 0.601 \\
\hline Multiparous & 85 & 34.7 & 62 & 32.8 & 147 & 33.9 & 0.680 \\
\hline Large multiparous & 79 & 32.2 & 58 & 30.7 & 137 & 31.6 & 0.729 \\
\hline \multicolumn{8}{|l|}{ Gestational age $(A W)$} \\
\hline$<37$ & 52 & 21.2 & 42 & 22.2 & 94 & 21.7 & 0.914 \\
\hline $37-42$ & 102 & 41.6 & 84 & 44.4 & 186 & 42.9 & 0.729 \\
\hline$>42$ & 21 & 8.6 & 23 & 12.2 & 44 & 10.1 & 0.368 \\
\hline Unknown & 70 & 28.6 & 40 & 21.2 & 110 & 25.3 & \\
\hline Mean and standard deviation & \multicolumn{2}{|c|}{$38.8 \pm 3.7$} & \multicolumn{2}{|c|}{$39.5 \pm 3.3$} & \multicolumn{2}{|c|}{$\mathrm{t}=0.08$} & 0.088 \\
\hline \multicolumn{8}{|l|}{ Cesarean antécedent } \\
\hline Once & 31 & 12.7 & 20 & 10.6 & 51 & 11.8 & 0.506 \\
\hline Two times & 6 & 2.4 & 3 & 1.6 & 9 & 2 & 0.905 \\
\hline Thrice & 2 & 0.8 & 2 & 1.1 & 4 & 0.9 & 0.806 \\
\hline Total & 39 & 15.9 & 25 & 13.2 & 64 & 14.7 & 0.539 \\
\hline \multicolumn{8}{|l|}{ Admission mode } \\
\hline Direct & 170 & 69.4 & 97 & 51.3 & 267 & 61.5 & 0.0007 \\
\hline Reference & 2 & 0.8 & 2 & 1.1 & 4 & 0.9 & 0.8063 \\
\hline Emergency evacuation & 73 & 29.8 & 90 & 47.6 & 163 & 37.6 & 0.0001 \\
\hline \multicolumn{8}{|l|}{ Prenatal consultation } \\
\hline Any & 121 & 49.4 & 36 & 19 & 157 & 36.2 & 0.0000 \\
\hline $1-2$ & 9 & 3.6 & 2 & 1.1 & 11 & 2.5 & 0.393 \\
\hline$\geq 3$ & 69 & 28.2 & 68 & 36 & 137 & 31.6 & 0.007 \\
\hline Not indicated & 46 & 18.8 & 83 & 43.9 & 129 & 29.7 & \\
\hline
\end{tabular}

Table 2. Maternel and perinatal prognostic.

\begin{tabular}{cccccccc}
\hline & \multicolumn{2}{c}{ Kasansa } & \multicolumn{2}{c}{ Tshilenge } & \multicolumn{2}{c}{ Total } & \multirow{2}{*}{ p-value } \\
\cline { 2 - 6 } & Effective & $\%$ & Effective & $\%$ & Effective & $\%$ & \\
\hline Maternel & & & & & & & 0.7844 \\
Living & 1380 & 99.5 & 671 & 99.4 & 2051 & 99.4 & \\
Death & 7 & 0.5 & 4 & 0.6 & 11 & 0.5 & \\
Perinatal & & & & & & & 0.0000 \\
Living & 1321 & 95.2 & 595 & 88.2 & 1916 & 92.9 & \\
Death & 66 & 4.8 & 80 & 11.8 & 146 & 7.1 & \\
\hline
\end{tabular}




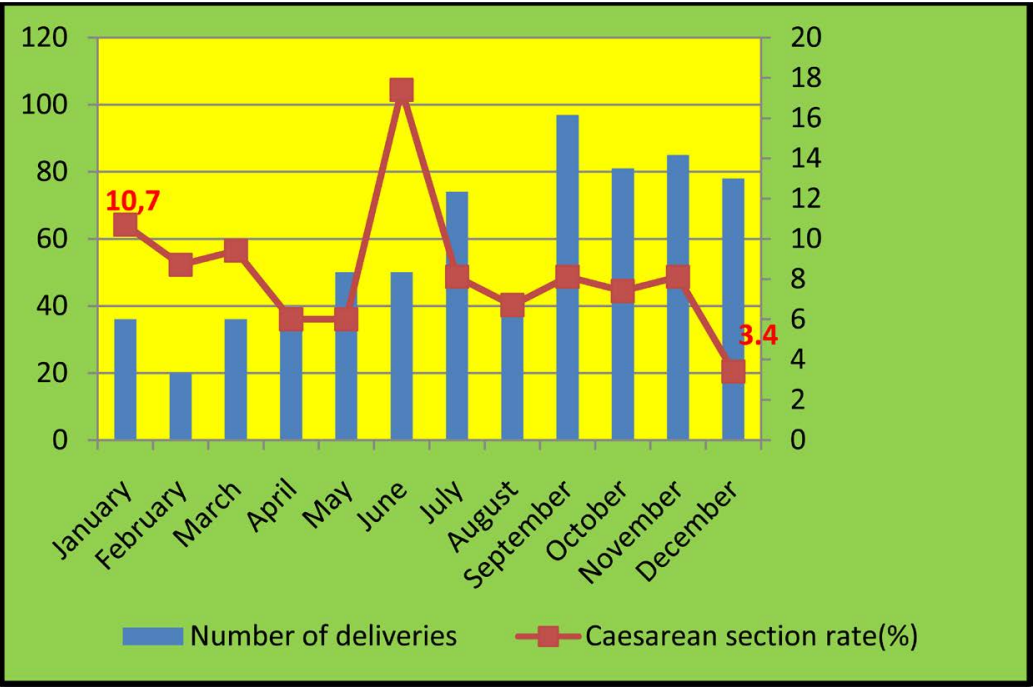

Figure 1. Monthly evolution of Caesarean section rate in Kasansa in 2015.

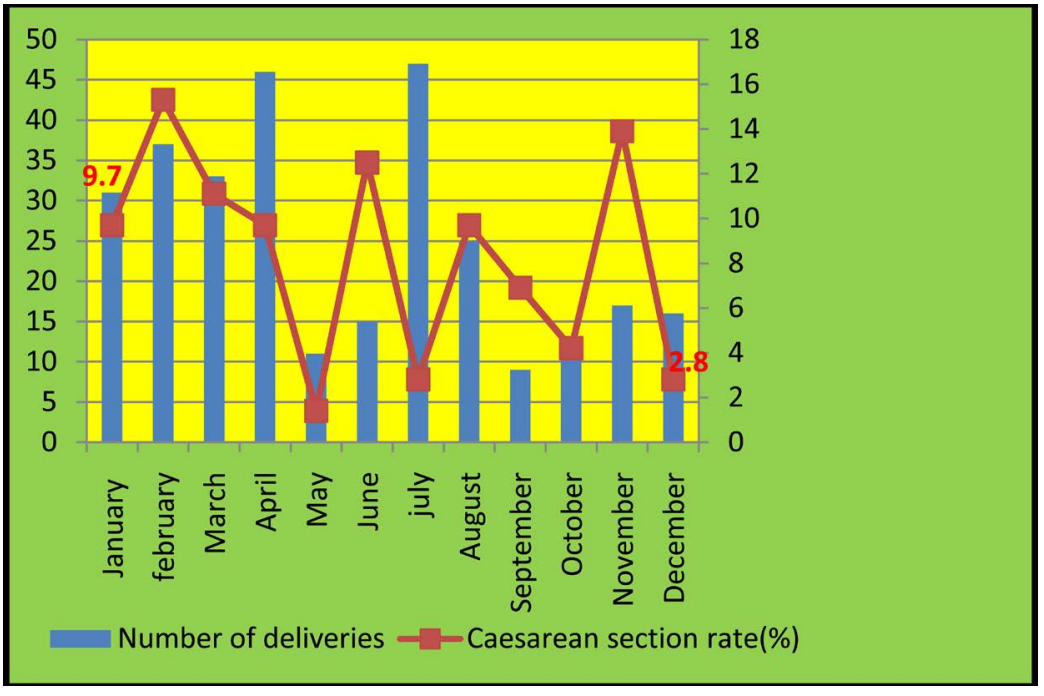

Figure 2. Monthly evolution of Caesarean section rate in Tshilenge in 2015.

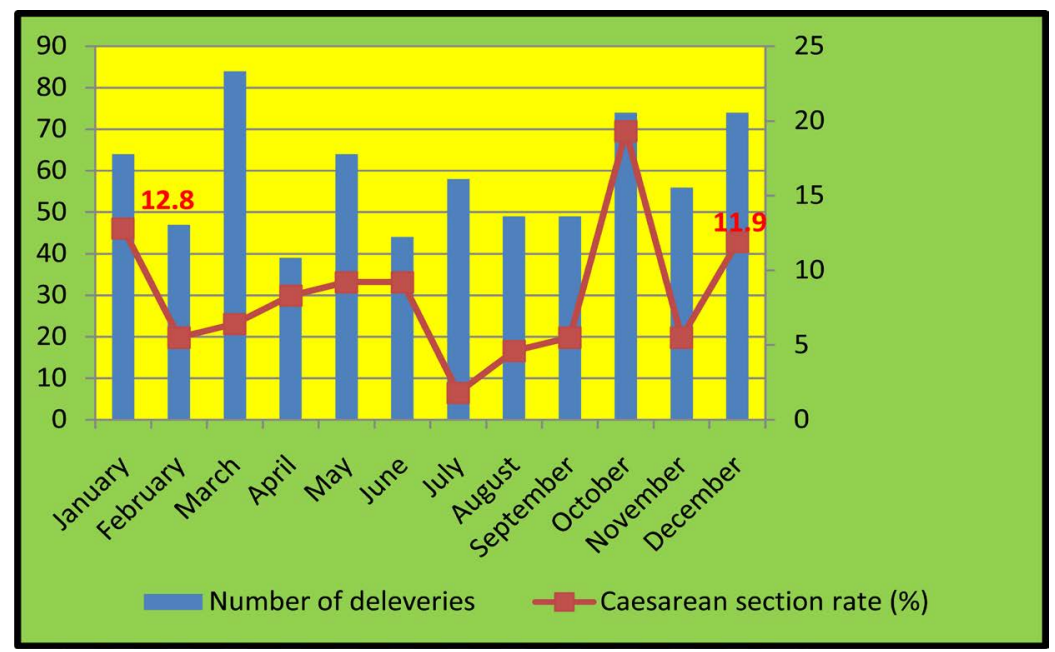

Figure 3. Monthly evolution of Caesarean section rate in Kasansa in 2016. 


\subsection{Perinatal and Maternal Mortality Related to Caesareans}

In 2015, out of 984 deliveries, we counted 73 perinatal deaths, a rate of 74 per 1000 births. Thus, perinatal mortality, which was 105 per 1000 in January, increased to 32 per 1000 births in December (Figure 5).

In 2016, 73 perinatal deaths were recorded among 1078 deliveries. The perinatal mortality rate was 68 per 1000. This rate, which was 83 per 1000 in January, increased to 40 per 1000 births in December 2016 (Figure 6).

In 2015, maternal clinics in Kasansa and Tshilenge recorded 7 maternal deaths, representing a mortality of 768/100,000 live births. The maternal death

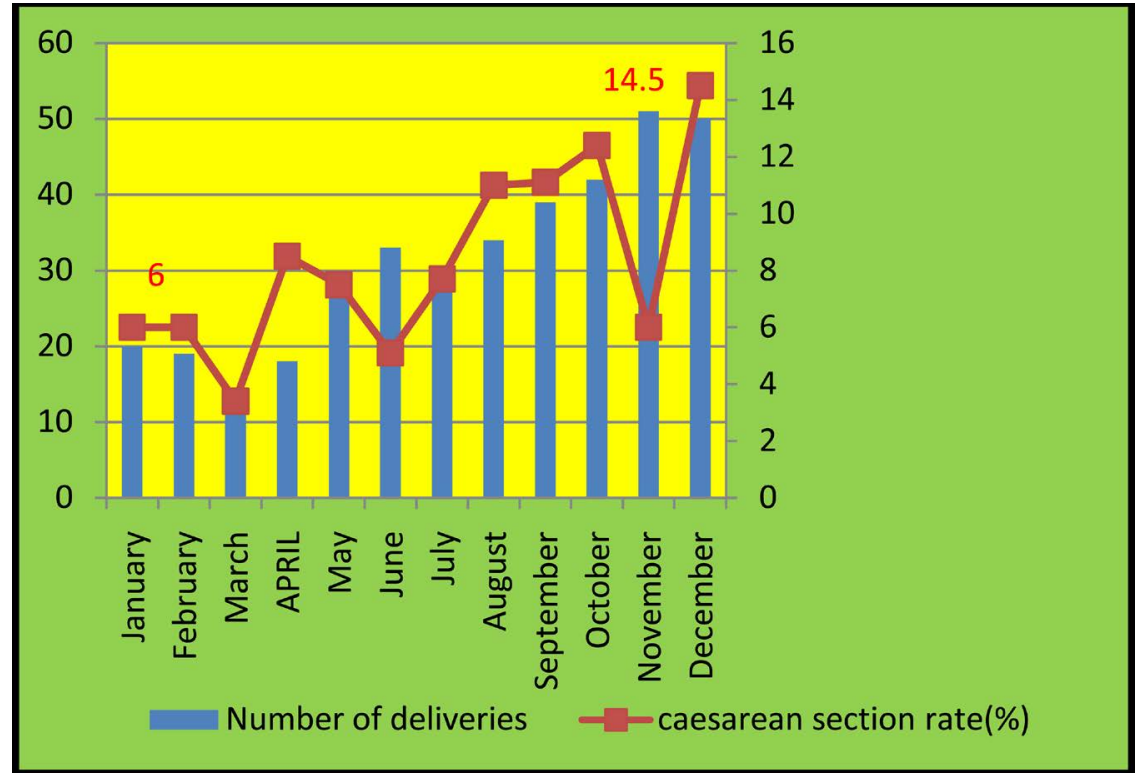

Figure 4. Monthly evolution of Caesarean section rate in Tshilenge in 2016.

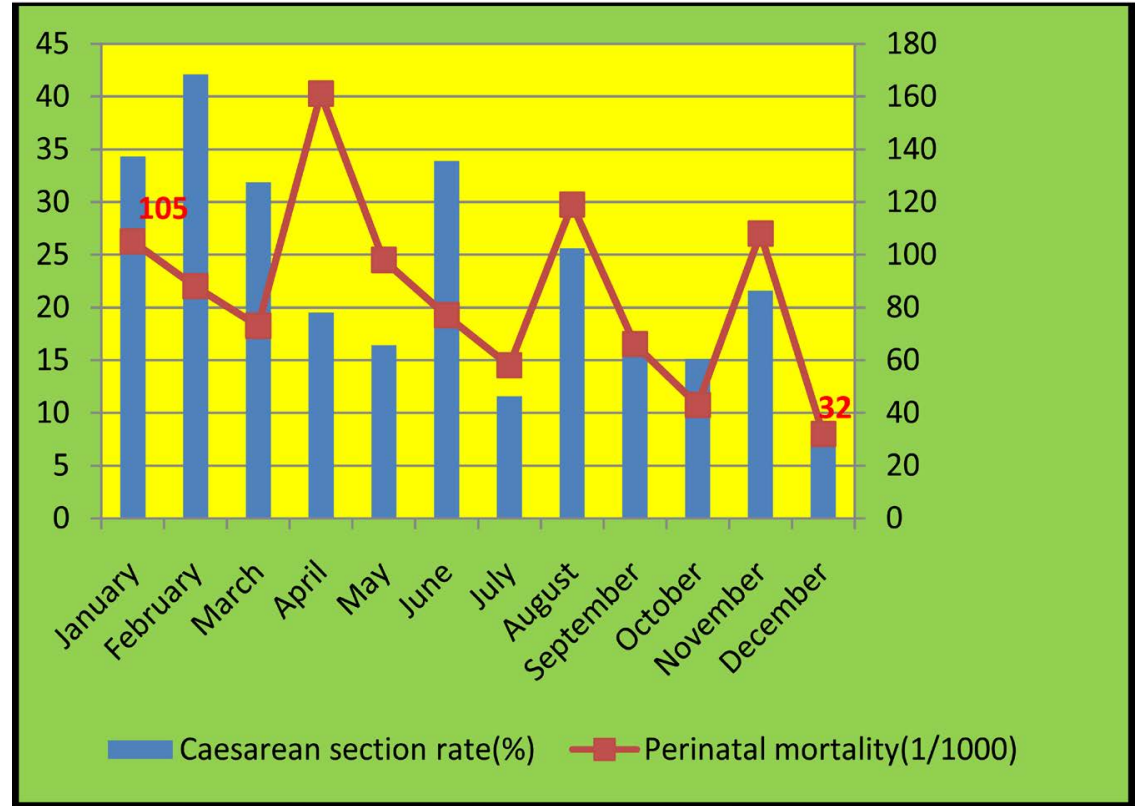

Figure 5. Perinatal mortality related to Caesareans in 2015. 


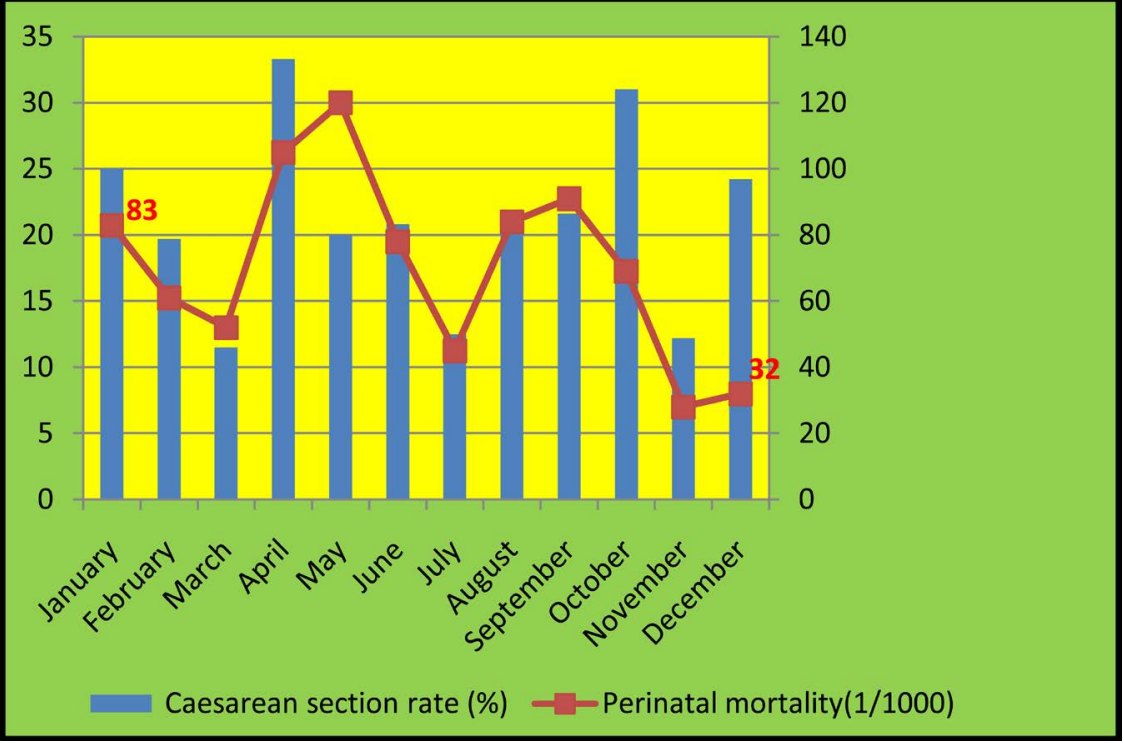

Figure 6. Perinatal mortality related to caesareans in 2016.

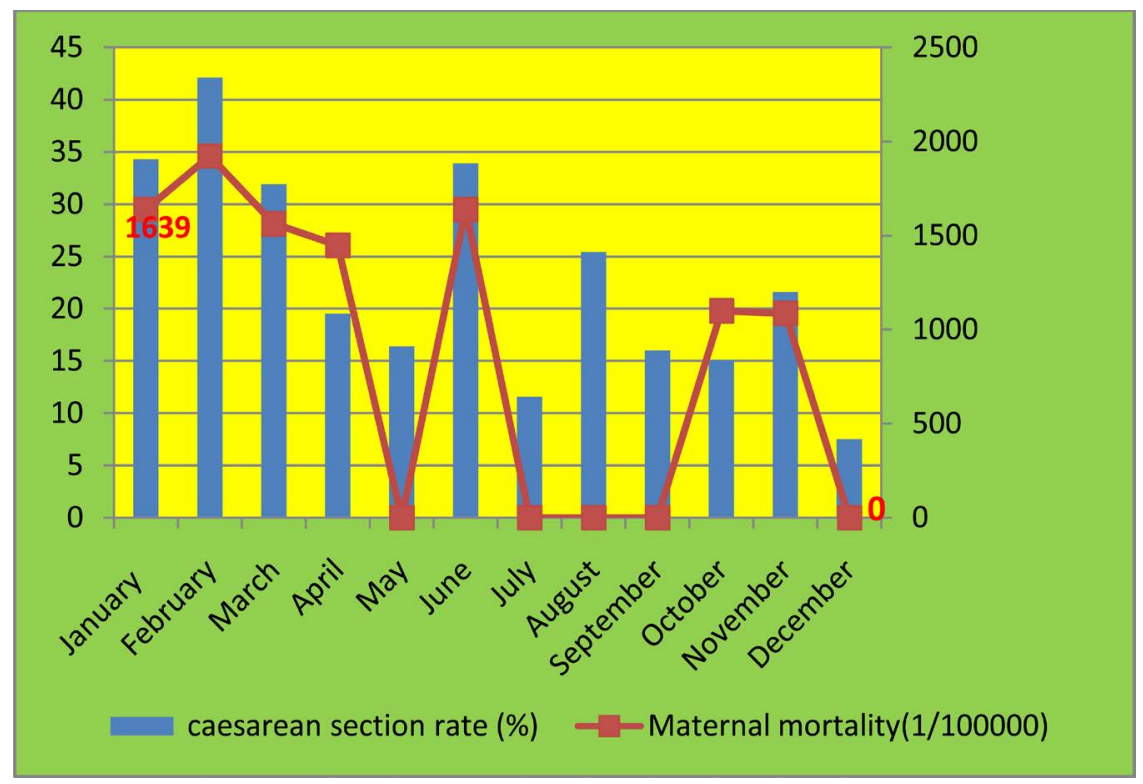

Figure 7. Maternal Mortality for Caesareans in 2015.

from 1639/100,000 births in January to 0/100,000 births in December (Figure 7).

In 2016, 4 maternal deaths were recorded, representing a maternal mortality of 398/100,000 births. It had increased from 1299/100,000 births at the beginning of the year to 833/100,000 births in December (Figure 8).

\section{Discussion}

\subsection{Characteristics of the Patients}

This study was initiated to identify the epidemiological situation and the evolution of caesarean section rates in rural health areas of Tshilenge and Kasansa. The main results show in the structures where our study was conducted, during 


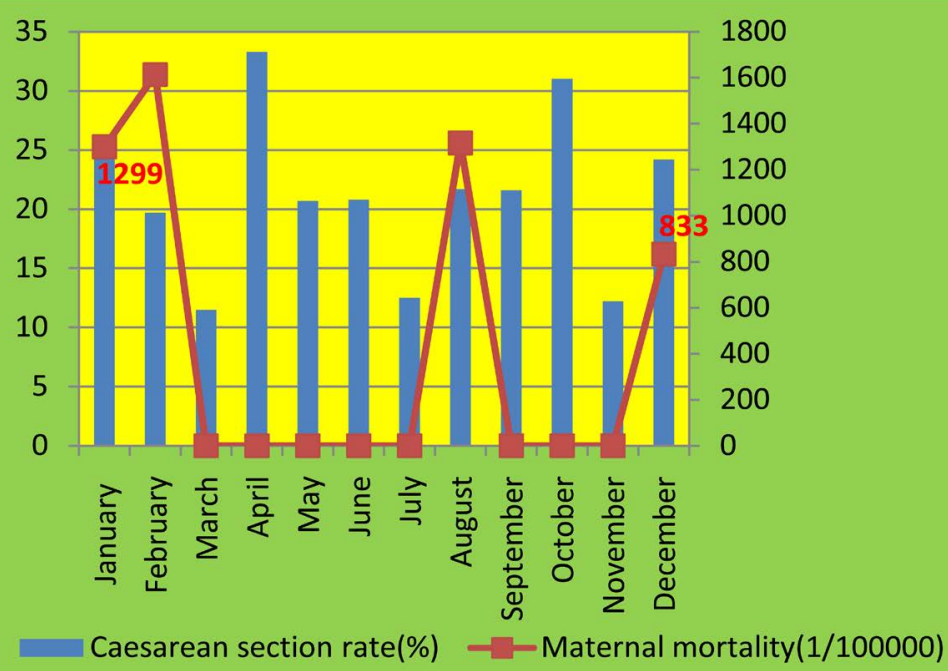

Figure 8. Maternal mortality related to Caesareans in 2016.

the period concerned, a constant decline in the number of deliveries by caesarean section. A study conducted at the same time in the same structures with the same sample revealed a rate of $21.1 \%$ for all two structures (Kasansa and Tshilenge) [14]. This almost general decline in our series is explained by the fear of this intervention in African women in general and the "Taboo" character attributed to them. The idea that giving birth is "giving birth by the vaginal way" means that this intervention, which is essential to save the life of the mother and the child, is most often carried out urgently, and a caesarean section of convenience is generally rare [15]. Contrary to the phenomenon observed in the industrialized countries and some emerging countries where there is a plague of caesarean section, one of the explanations of which would be the demographic changes occurring in these countries which have reduced the average number of children per family so that each child becomes and that the limitation of the number of births often rightly or wrongly imposed by caesarean section ceases to be poorly accepted [16] [17] [18]. The plausible explanation for the caesarean section rate increase observed in 2016 at the Tshilenge maternity ward would be the result of increased use of the structure by patients from surrounding health areas or the city. Mbujimayi following the SONU grant.

\subsection{Maternal and Perinatal Mortality Related to Cesarean Section}

In both structures, the decline in perinatal mortality is a phenomenon opposite to that experienced in industrialized countries, where, in parallel with the increase in caesarean section rates, perinatal mortality has declined significantly [5] [8] [9] [17] [19], he corroborates O'Driscoll et al. who have shown that in Dublin this mortality had improved without the rate of caesarean section increasing [20].

Like the perinatal mortality, in our series, maternal mortality experienced significant regressions during the study period until reaching the zero point at certain times despite the increasingly low rates of caesarean section. On the other 
hand, in the industrialized countries, the resurgence of caesarean section in recent decades has been accompanied by a proportional benefit for the mother-child couple, i.e. a dramatic decline in maternal and maternal mortality perinatal [21]. For caesarean section rates above $20 \%$, maternal mortality and perinatal mortality from 1990 to 2013 increased from 7.4 to 4.8 per 100,000 births and from 4.4 to 2.6 in Denmark, from 10 to 3 to 3.2 per 100,000 births and $4.6 \%$ o to $2.3 \%$ in Austria, 10.4 to 6.1 per 100,000 births and 4.5\%o to 2.7\%o in England and 15.6 to 8.8 per 100,000 births and $3.6 \%$ to $2.3 \%$ in France [12]. In our study it is difficult to evoke the same reasons as those of the industrialized countries for the improvement of maternal-infantile prognosis because the working conditions in the hospitals which we have observed are not very different, African environment in general and rural environment in particular. On the other hand, Cisse's study in Dakar revealed a considerable increase in the rate of caesarean section, which had no significant impact on overall maternal mortality (1411 deaths per 100,000 live births in 1992 as against 1394 deaths per 100,000 births 2001) and overall perinatal mortality (121 deaths per 1000 in 1992 compared to 116 deaths per 1000 births in 2001) [5].

\section{Conclusions}

The increase in caesarean section rate is a general phenomenon observed in most series of the literature. This evolution is justified mainly by an improvement in the prognosis of the mother-child pair. However, the majority of authors report high mortality and morbidity related to caesarean section compared to the vaginal approach.

In maternal clinics in Kasansa and Tshilenge, maternal and perinatal mortality remained low despite that monthly rates of caesarean sections were significantly lower in both years of study, with the exception to Tshilenge maternity hospital in 2016, which saw a $143,3 \%$ increase.

Thus, the price to pay for the improvement of the maternal prognosis goes rather by an improvement of the quality of the obstetric care and not by the increase of the number of the operative deliveries. This conduct will aim at a generalization of pregnancy surveillance; more rigorous care for high-risk pregnancies; informing the public of the dangers of attempting home deliveries and improving the health facilities of peripheral centers; and finally, a tendency to define and master the indications for cesarean section is of great value.

\section{Acknowledgements}

We would like to thank the staff of the Kasai Oriental Provincial Health Division and the Kasansa and Tshilenge hospitals for their collaboration in carrying out this study.

\section{Contribution of Our Study}

First multi-center study conducted in rural Kasai Oriental, which will assess the 
maternal and perinatal prognosis in our context.

\section{Conflicts of Interest}

The authors declare no conflict of interest.

\section{Contribution of the Authors}

Each author contributed to the realization of this work and all read and approved the final version

\section{References}

[1] Nwosu, C., Agumor, K., Aboyeji, A.P. and Ijaiya, M.A. (2004) Outcome of Caesarean Section in a Sub-Urban Secondary Health Care Facility in Nigeria. Nigeria Medicine Practice, 46, 77-79.

[2] Stanton, C.K., Sara, A. and Holtz S.A. (2006) Levels and Trends in Cesarean Birth in the Developing World. Stu Fam Plan., 37, 41-48.

https://doi.org/10.1111/j.1728-4465.2006.00082.x

[3] Marc, H. (2007) Operative Delivery. In: Alan, H.D. and Lauren, N., Eds., Current Obstetrics and Gynecological Diagnosis and Treatment, 10th Edition, MC Graw Hill Publishers, New York, 469-476.

[4] Labibe, L. (2012) Evolution of the Indications for Cesarean Section at the Souissi Maternity Ward between 1986 and 2010 (about 35,830 Cases). Thesis, Mohammed University, Rabat.

[5] Cissé, C., Ngom, P.M., Guissé, A., Faye, E.O. and Moreau, J.C. (2004) Reflections on the Evolution of Caesarean Section Rates in Africa: Example of Dakar University Hospital between 1992 and 2001. Obstetrics Gynecology Biology Reproduction, 32, 210-217.

[6] Kabongo, A.G., Bukasa, J.C., Banza, D.B., Kayembe, C., Mutombo, A., Wembonyama, S., et al. (2017) Caesarean in the Rural Environment of Eastern Kasai (DR Congo): Cover of the Needs and Quality of Services with Kasansa and Tshilenge. Journal of Clinical Obstetrics and Gynecology, 1, 40-47.

[7] Brooch, D.-E., Courtois, L., Maillet, R. adn Riethmuller, D. (2008) Caesareans. Encyclopedia. Obstetrics Surgery Medicine, 5, 102-110.

[8] Kizonde, K., Kinekinda, X., Kimbala, J. and Kamwenyi, K. (2006) Cesarean Section in Africa: Example of the Sendwe Central Maternity Hospital in Lubumbashi-DR Congo. Medicine of Black Africa, 53, 293-298.

[9] Zongo, A., Kouanda, S., Fournier, P., Traore, M., Sondo, B. and Dumont, A. (2014) Trends in Institutional Caesarean Delivery among Low-Risk Patients in Senegal and Mali: Secondary Analysis of a Cluster-Randomized Trial (Quarry). Journal Women's Health Care, 3, 192-199. https://doi.org/10.4172/2167-0420.1000192

[10] Guzerman, M. (2006) Five Years the Term Breech Triad: The Rise and Fall of a Randomized Controlled Trial. Journal of Obstetric Gynecology, 194, 20-25.

[11] Carayol, M. (2004) Changes in the Rate of Caesarean Section before Work for Term Seat Presentation in France 1972-2003. Journal of Gynecology Obstetrics and Biology of Reproduction, 29, 30-39.

[12] Goffiner, F., Blondel and Break, G. (2001) Questions Posed by a Controlled Trial by Hannah et al on the Systematic Practice of a Caesarean Section in the Event of a Siege. Journal of Gynecology Obstetrics Biology Reproduction, 30, 187-190. 
[13] Keita, N., Diallo, F.D., Gandaho, E. and Leno, D.W.A. (2014) Cesarean Section in Africa: Example of Guinea, Conseil National des Gynécologue et Obstétriciens Français, 38th National Days, Paris.

[14] Gafni, A., Goeree, R., Myhr, T., Hannah, M., Blackhouse, G., Willan, A., et al. (1997) Induction of Labor versus Expectant Management for the Rupture of Membranes at Term: An Economic Evaluation. Canadian Medical Association Journal, $157,1519-1525$.

[15] Souza, J.P., Gülmezoglu, A., Lumbiganon, P., Laopaiboon, M., Carroli, G., Fawole, B., et al. (2010) Caesarean Section without Medical Indications Is Associated with an Increased Risk of Adverse Short-Term Maternal Outcomes: the 2004-2008 WHO Global Survey on Maternal and Perinatal Health. BMC Medicine, 8, 71. https://doi.org/10.1186/1741-7015-8-71

[16] Ecker, J.L. and Frigoletto, F.D. (2007) Cesarean Delivery and the Risk-Benefit Calculus. The New England Journal of Medicine, 356, 885-888. https://doi.org/10.1056/NEJMp068290

[17] Mi, J. and Liu, F. (2014) Rate of Caesarean Section Is Alarming in China. The Lancet, 383, 1463-1464. https://doi.org/10.1016/S0140-6736(14)60716-9

[18] Bambara, M., Fongan, E., Dao, B., Ouattara, S., Ouattara, H., Lankoande, J. and Kone, B. (2007) Caesarean Section in Africa: About 440 Cases at CHUSS Maternity Hospital in Bobo-Dioulasso (Burkina Faso). Medicine of Black Africa, 54, 343-348.

[19] Waniez, P., Wurtz, B. and Brustlein, V. (2006) Abuse of Caesarean Section in Brazil. Geographical Dimensions of a Medical Aberration. Cahiers Santé, 16, 21-31.

[20] O'Driscoll, K. and Foley, M. (1983) Correlation of Decrease in Perinatal Mortality and Increase in Cesarean Section Rates. Journal of Obstetric Gynecology, 61, 1-5.

[21] Hannah, M.E., Hannah, W., Hewson, S.A., Hodnett, E.D., Sagital, S. and William, A.R. (2000) Planned Caesarean Section versus Planned Vaginal Birth for Breech Presentation at Term: A Randomized Multicenter Trial. The Lancet, 356, 1375-1378. https://doi.org/10.1016/S0140-6736(00)02840-3 